\title{
Implementation of Soldier Assisting Device using LoRa with SOS Functionality
}

\author{
G. Akilandeswary ${ }^{1}$, Joel Soloman Raj. $\mathbf{A}^{2}$, Harish Kumar. $\mathrm{K}^{3}$ \\ ${ }^{1,2,3}$ Department of Electronics and Communication Engineering, \\ St. Joseph's Institute of Technology, Chennai, Tamilnadu, India \\ Email: akilasrinivasan12@gmail.com ${ }^{1}$, joelsoloman1998@gmail.com², francishaarish@gmail.com ${ }^{3}$
}

\begin{abstract}
The strength of a nation is in its military powers, including soldiers in air, water, and land. To monitor such soldiers, a small and efficient system is proposed. This system is mountable to the soldier and monitors the health parameters and location of the soldier. Some useful to the soldier are also incorporated into this system, which includes metal detection for landmines and the ability to send an SOS signal to the control room. The implementation of the LoRa (Long Range) technique helps us to transmit the signals from the soldier to the control room with a low data rate, at long distances. By using LoRa we can make a system that is better at consuming low power and transmit at a high transmission power. The health monitoring system comprises of heart rate monitoring, pulse monitoring, temperature measurement, and motion detection. Motion detection helps in the identification of the fatigue levels of the soldier in the war zone. Metal detection is assisted by the use of an Inductive proximity sensor. These combinations of devices help in the effective tracking of the soldier in the field and their parameters, thus contributing to the individual's increased survivability.
\end{abstract}

Keywords-LoRa, Arduino, Monitoring, SOS, Assisting, Soldier.

\section{INTRODUCTION}

Our Indian army is the fourth largest and well organized and influential compared to other countries in the world. This is possible only when the life of each soldier is safeguarded. Even though technologies grow, the lack of communication and information unavailability during a conflict on the battlefield increases the soldiers' death rate. It is observed that the soldier's death rate increases due to the injuries caused in the battle than the direct assaults. This can be decreased only when real-time information is precisely transferred to the control room where the internet cannot be a major part. So, developing various kits has been a significant concern for the safety of the soldiers.

A soldier's life can be saved only when the complete information such as body temperature, pulse rate, location and various vitals about him is known to the control room in real-time so that they can take immediate remedial action depending on his conditions. In the past few years, technologies such as RF transceivers, ZigBee, WalkieTalkie, GSM are used for soldier's assistance but they had many disadvantages, such as high installation cost, high noise interference, loss of signal and bulky to carry.

So, to overcome these factors, a technology called LoRa is used to transmit data. It draws low power, has high security, and covers long-range than others. This

Vol. 4 (5), November 2020, www.ijirase.com
The system consists of various sensors to sense the soldier's vitals and transmits through LoRa in real-time to the control room.

\section{LITERATURE SURVEY}

Many academicians made their efforts and reported concepts in monitoring and tracking soldiers' parameters on the battlefield.

The work in [1] Niket Patil and Brijesh Iyerproposed the soldier's tracking and monitoring system using the Internet of Things. In that system, they used biomedical sensors to sense the body parameters to sense the soldier's body condition. This information is also stored in the cloud for future reference. A GPS receiver is also employed for tracking him based on his location. Node MCU is used for the computation and transmit data to the cloud and to the base station.

In [2] T. Dharshini, H. Zahir and others have proposed a system that monitors and tracks a soldier with the same biomedical sensors. In addition to those sensors, they also added a motion sensor that detects the soldier's motion on the battlefield. In this IoT, the concept is used for the transmission of the data. GSM is placed in the soldier's kit so that the soldier's information can be directly sent to mobile phone vis Short Messaging Service.

In [3] Hock Beng Lim, Di Ma, Bang Wang, Zbigniew Kalbarczyk, proposed a prototype smart helmet for monitoring soldier's health parameters that consists of several biomedical sensors that monitor and transmits. The helmet has an additional feature for sensing ECG (Electro 
Cardiogram) and EEG (Electro Encephalogram). This prototype uses Body Sensor Network for computation and another transmission of data. This helps in real-time monitoring of soldiers and this much helps in saving a soldier's life since a prototype of the helmet is used this prevent from head injury[4].

\section{THE PROPOSED SYSTEM}

The system proposed here monitors, tracks, and also assists the soldiers on the battlefield using LoRa technology. The control room acquires and monitors the data that is being transmitted from the soldier. The GPS receiver guides the soldier in maintaining his direction, preventing him from losing his way. Other than GPS, the soldier is also loaded with several biomedical sensors to monitor and observe his health parameters on the battlefield. Along with these sensors, several other sensors are also fixed to observe the surroundings to ensure that his way is safe enough. The biomedical sensors used here are the LM35- temperature sensor to observe his body temperature and pulse rate sensor for observing the heartbeat[5].

Other sensors include gas sensors to detect and alert the soldier if he is surrounded by poisonous gases such as carbon monoxide. Accelerometer for observing his movement in the battlefield and metal sensor for detecting landmines. Another feature that this device gets is that the SOS. This is nothing but a distress signal which is sent to the control room in case of his emergency to back him up or for immediate action. This is useful when he sees any danger visually even-though his body parameters are good. When the SOS button is pressed for help, his location is sent to the control room so that the rescue force can assist him directly. This system has two parts one is the soldier's unit or the transmitter unit and the control room unit or receiver unit[6].

The microcontroller processes all the data collected from various sensors. Here Arduino (ATmega328P) microcontroller is used. This choice is made for various reasons. It is an open-source platform, easily available at low cost, easy to use, and with high interfacing capability. The microcontroller plays an important role in processing and transmitting the data through LoRa module. If any parameter exceeds the threshold, an alert is sent to the control room so that they can assist the soldier in return[7].

\section{A. Advantages}

\section{- $\quad$ Less complicated than existing systems}

- Low cost and easy to mount

- High security and Long Range
- It draws low power and doesn't need any form of internet to work.

\section{B. The Algorithm}

- Measure the body parameters such as temperature and heart rate using LM35 temperature sensor and pulse rate sensor and transmit to the control room.

- The soldier's exact location is tracked and displayed in soldier's kit and to the control room.

- The gas sensor and metal sensors detect poisonous gas and landmines and send the information to the base station.

- The sensed values are computed, recorded, compared with the threshold values and an alert is sent to the control room. If the readings cross the threshold, an alert is automatically sent.

- When pressed, the SOS button gives the control room an immediate alert and the location to back up in emergency situations.

\section{Block Diagram}

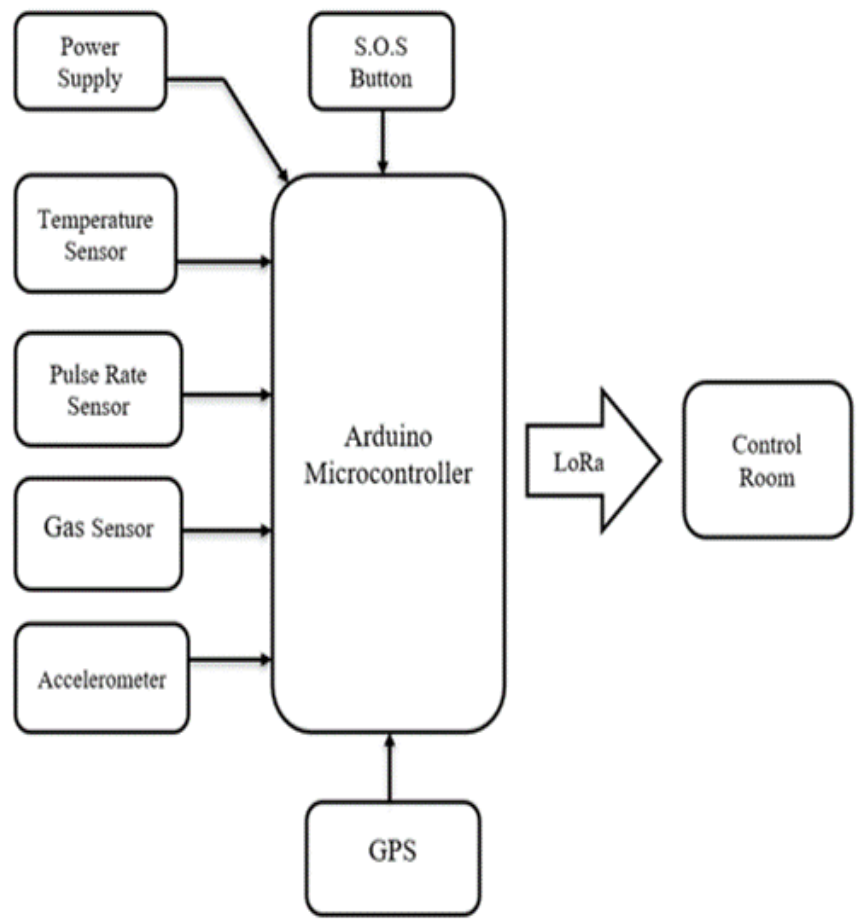

Fig.1. Block Diagram - Overall Operation 


\section{SYSTEM DESCRIPTION}

\section{A. Arduino microcontroller}

Arduino is an open-source electronic prototype platform based on easy-to-use hardware and software. It consists of a circuit board and a microcontroller, which can be programmed and a ready-made software called Arduino Integrated Development Environment, which is used to write and upload the computer code to the physical board[8].

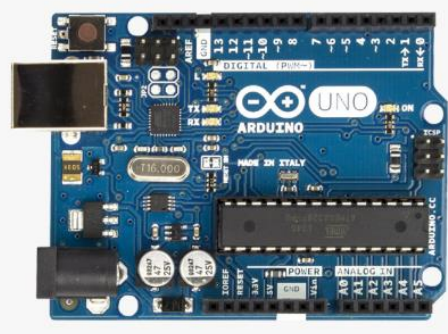

Fig. 2. Arduino Uno

\section{B. Temperature Sensor- LM35}

The Temperature Sensor LM35 is a precision integratedcircuit temperature device with an output voltage linearly proportional to the centigrade temperature. It is widely used to measure body temperature and temperature can be measured more accurately than with the thermistor. The temperature sensor LM35 has a wide temperature range of $-55^{\circ} \mathrm{C}$ to $150^{\circ} \mathrm{C}[9]$.

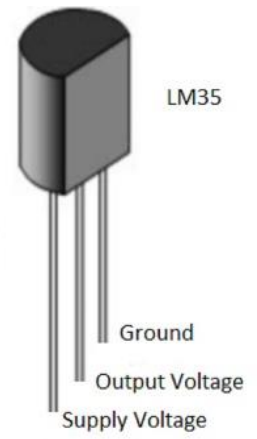

Fig. 3. Temperature Sensor

\section{Pulse Sensor}

The pulse sensor is used to measure the heart rate of the soldier. It is an optical sensor that uses a methodology called photoplethysmography to measure the heart rate. The sensor has two sides, on one side, the LED is placed along with an ambient light sensor, and on the other side we have some circuitry. This circuitry is responsible for the amplification and noise cancellation work. The LED emits light that will

Vol. 4 (5), November 2020, www.ijirase.com fall on the vein directly. The blood flow reflects this light and finally, our heartbeat is calculated.[9]

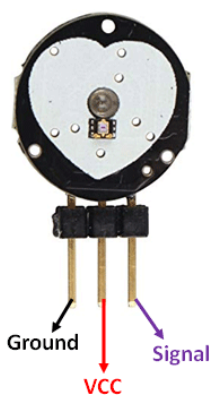

Fig. 4. Pulse sensor

\section{D.Gas Sensor}

A gas sensor is a device that detects the presence or concentration of gases in the atmosphere. Based on the gas concentration, the sensor produces a corresponding potential difference by changing the resistance of the material inside the sensor, which can be measured as output voltage. Based on this voltage value, the type and concentration of the gas can be estimated. Here the gas sensor is used to find out the concentration of harmful gas present to ensure soldier's safety[10].

One of the deadliest gas is Carbon Mono-oxide. Here the Carbon Mono-oxide is given first preference for finding, followed by other gasses in the surrounding.

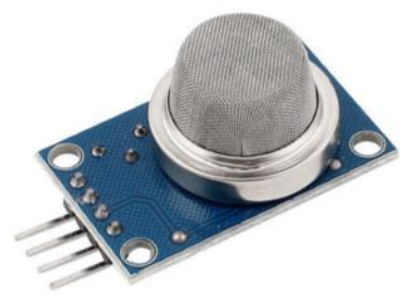

Fig. 5. Gas Sensor

\section{E. Accelerometer}

Accelerometers are integrated circuits or modules used to measure an object's acceleration to which they are attached. They are used in applications including vehicle dynamics, mobile phone orientation detection, image stability, tilt, tap detection and anti-theft devices. Accelerometers are available in several technologies, including piezoelectric, piezoresistive and variable capacitance. The accelerometer consists of three axes, namely $\mathrm{X}, \mathrm{Y}$ and $\mathrm{Z}$ this is employed here to monitor the soldier's movement in the battlefield. If any of the axes cross the threshold, then the soldier's activity 
is abnormal. The accelerometers are great in finding the exact direction of the soldier[11].

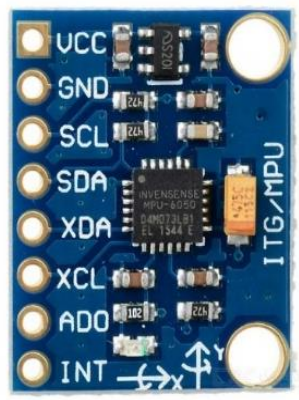

Fig.6.Temperature Sensor

\section{F.GPS Receiver}

Expanded as "Global Positioning System", GPS is a satellite navigation system used to determine an object's ground position. GPS technology was first used by the United States military in the 1960s and expanded into civilian use over the next few decades. Today, GPS receivers are included in many commercial products, such as automobiles, smartphones, exercise watches, and GIS devices. The GPS satellite broadcasts a message that consists of the satellite's current position, orbit, and exact time. A GPS receiver combines the broadcasts from multiple satellites to calculate its precise position using triangulation. Three satellites are required to determine a receiver's location, though a connection to four satellites is ideal since it provides greater accuracy.

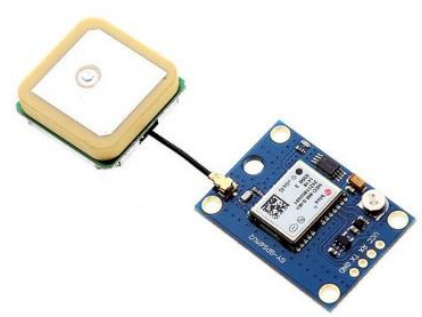

Fig. 7. GPS Receiver

\section{G. SOS Button}

The SOS feature consists of a button in the soldier's kit and an alert in the base station. This feature allows the soldier to get backed up during emergencies or for medical assistance.

If the soldier presses the SOS button, a distress signal from the transmitter is sent to the receiver creating an alert that immediate backup is required. Along with the alert, the transmitter uses the GPS receiver to transmit the soldier's exact location. This feature greatly helps the soldier

Vol. 4 (5), November 2020, www.ijirase.com visualize or sense any danger even though his body and surrounding parameters are normal.

\section{H. LoRa Transmitter}

LoRa expanded as Long Range, is a spread spectrum modulation technique derived from chirp spread spectrum technology. These long-range transmitters are about 10+ kilometers when in line of sight. These can penetrate dense urban areas making them more accessible. It consumes low power and provides security to the information that is transmitted by using end-to-end AES encryption. The LoRa transmitter has a frequency of $433 \mathrm{Mhz}$ and consumes about 1.3-3.6 volts. It has excellent blocking immunity, preamble detection, and a built-in synchronizer. It has a working temperature of $-40^{\circ} \mathrm{C}-80^{\circ} \mathrm{C}$.

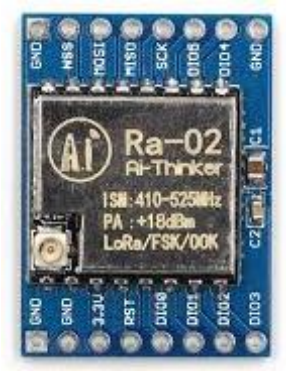

Fig 8. LoRa Transmitter

\section{Control Room Unit}

The control room serves as a monitoring and tracking station of the soldier. All the data sensed from the soldier are computed and transmitted using the LoRa transmitter and received in the control room via the LoRa receiver. There, a microcontroller is employed for decoding the information and to display this information. There the officers can observe the sensed data and track the status of the soldier.

\section{RESULTS AND DISCUSSION}

Since Soldier monitoring and tracking plays a vital role in safeguarding him from external danger in the battlefield, A system is designed and implemented to cover all the areas of sensing the soldier and environment surrounding him. This system consumes low power a transmits them in a secure way for a longer distance, thus making a monitoring and tracking system more reliable with advancements in communication and embedded technology

\section{A. Transmitted data}

The below figure shows the data obtained from various sensorsand transmitted through LoRa transmitter. The 
transmitted data include readings from gas sensor, temperature sensor, GPS receiver, accelerometer, metal sensor. These readings were sent to the receiver as a string for easy data transmission. Overall a $93 \%$ of accuracy has been obtained.

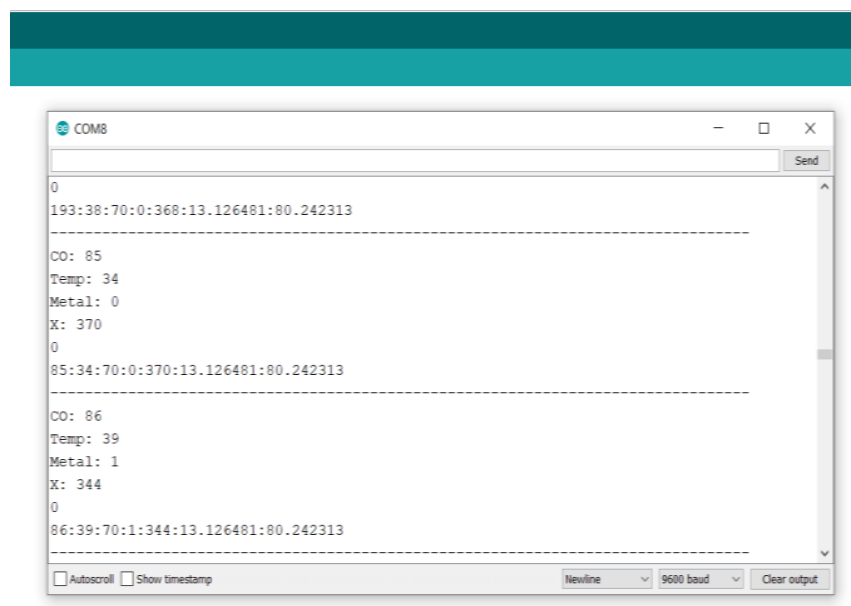

Fig.9. Serial Monitor Output of Transmitted Data

\section{B. Received data}

The data received showed the accurate information that is transmitted from the transmitter. The shared string that consisted of all the readings is decoded, separated and shown through the serial monitor. The serial monitor display of the received signal can be used as the control room's display; this display is informative enough to show all the soldier's parameters. This display of received data shows only the transmitted data. A separate collection is offered for the working of the SOS feature when the button is pressed.

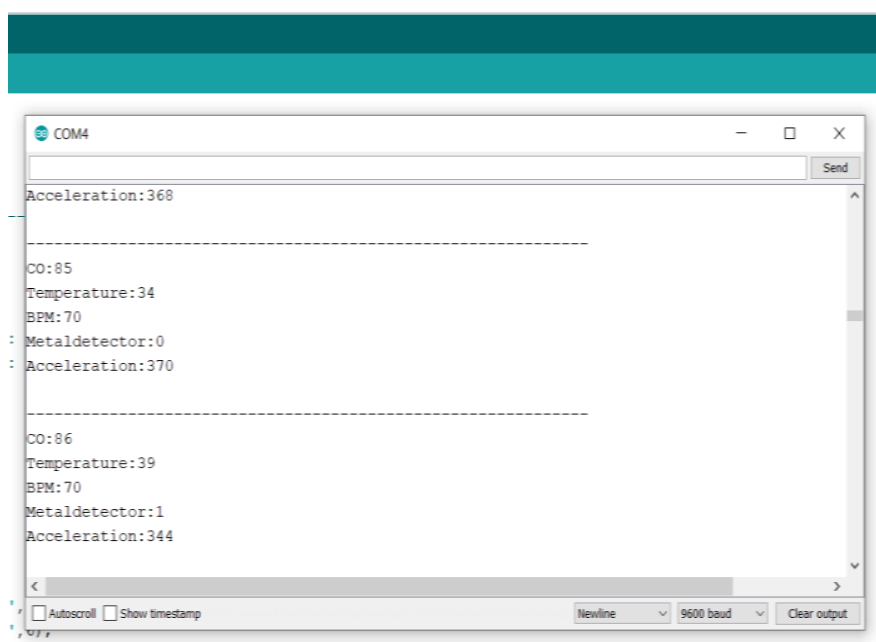

Fig. 10. Serial Monitor Output of Received Data

\section{Received SOS data}

Vol. 4 (5), November 2020, www.ijirase.com
The Below figure shows the data or requisition of soldier's when the SOS button is pressed. When pressed, an alert message along with the location is sent and displayed in the receiver's monitor.

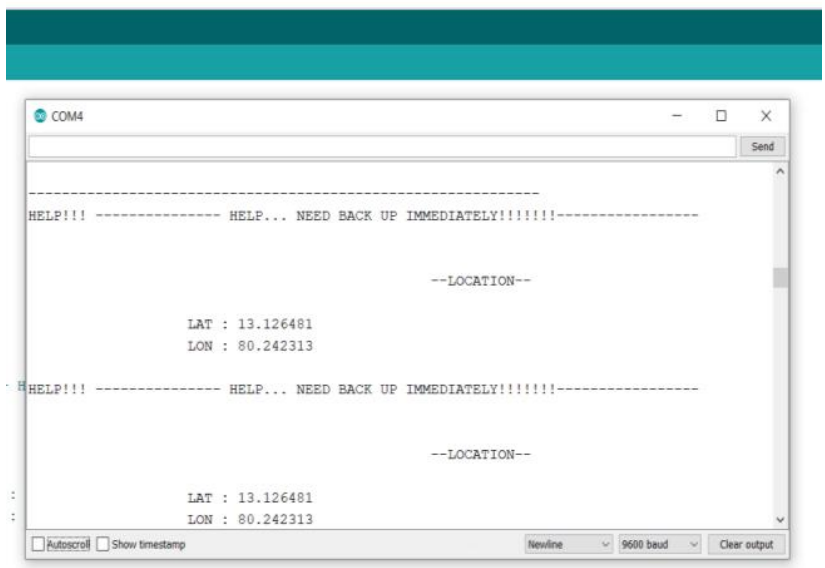

Fig. 11. Serial Monitor Output of Received Data when SOS Button is Pressed.

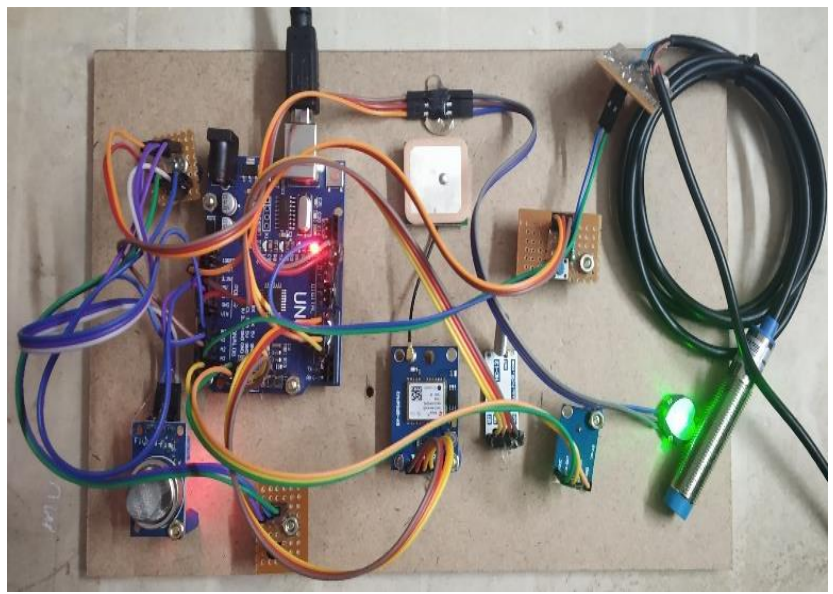

Fig. 12. Proposed Prototype Transmitter in Action.

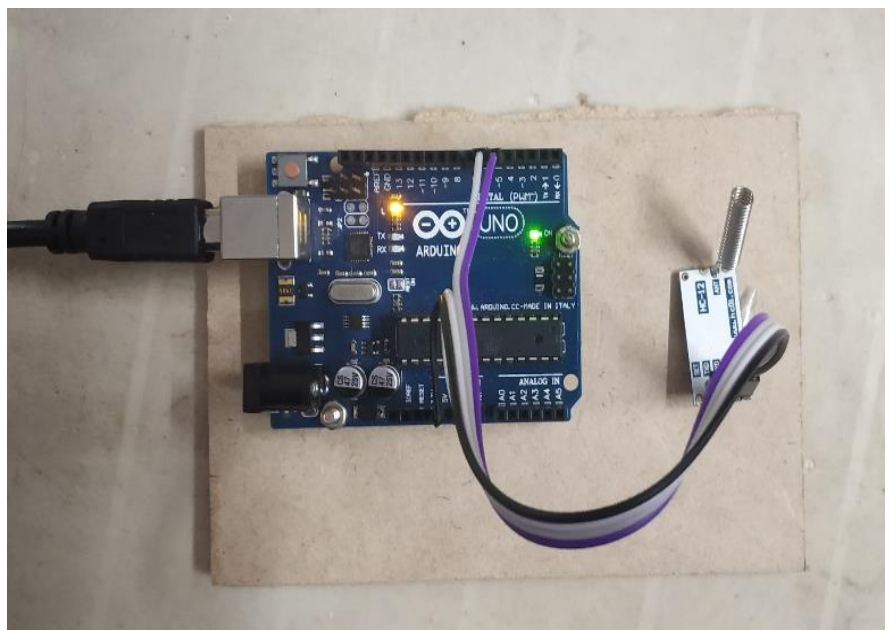

Fig. 13. Proposed Prototype Receiver in Action\ 764 


\section{CONCLUSION AND FUTURE SCOPE}

Thus, the proposed system titled "Implementation of soldier assisting device using LoRa with SOS functionality" is a reliable soldier monitoring system and assisting him on the battlefield. This system consumes low power and security in transmitting the information to the control room. It also communicates to a more extended range and provides an SOS feature to immediately create an alert in the control room and back him up in emergency situations. The proposed system helps greatly for a soldier who is assigned to spy enemy camps and for a soldier in reconnaissance. With the advancements in embedded and communication technology, this system offers high reliability, security, monitoring, tracking and assistance, thus increasing the survivability rate and protecting valuable life. In the future, this prototype can be reprogrammed to increase the efficiency of the work. The scope can also be increased by making the device more compact and wearable and decreasing data transmission errors.

\section{ACKNOWLEDGMENTS}

We want to express our gratitude to the Department of Electronics and Communication Engineering, St. Joseph's Institute of Technology, for their assistance and encouragement. We would also like to thank our guide staff Mrs. G. Akilandeswary., M.E., (Ph.D.)., who encouraged us and gave her full support during the development. At last, we thank our colleagues who contributed to the success of our project.

\section{REFERENCES}

[1]N. Patii and B. Iyer, "Health monitoring and tracking system for soldiers using Internet of Things(IoT)," 2017 International Conference on Computing, Communication and Automation (ICCCA), Greater Noida, 2017, pp. 1347-1352

[2]T. Dharsni, H. Zakir, P. Naik, Mallikarjuna and Raghu, "Soldier Security and Health Monitoring," 2018 International Conference on Design Innovations for 3Cs Compute Communicate Control (ICDI3C), Bangalore, 2018, pp. 37-40.

[3] H. B. Lim, D. Ma, B. Wang, Z. Kalbarczyk, R. K. Iyer and K. L. Watkin, "A Soldier Health Monitoring System for Military Applications," 2010 International Conference on Body Sensor Networks, Singapore, 2010, pp. 246-249.

[4]Wahyudi, M. S. Listiyana, Sudjadi and Ngatelan, "Tracking Objectbased on GPS and IMU Sensor," 2018 5th International Conference on Information Technology, Computer, and Electrical Engineering (ICITACEE), Semarang, 2018, pp. 214-218

[5]A. Lavric and V. Popa, "Internet of Things and LoRaTM lowpowerwide-area networks challenges," 2017 9th International Conference on Electronics, Computers and Artificial Intelligence (ECAI), Targoviste, 2017, pp. 1-4.

[6] L. Li, J. Ren and Q. Zhu, "On the application of LoRa LPWAN technology in Sailing Monitoring System," 2017 13th Annual
Conference on Wireless On-demand Network Systems and Services (WONS), Jackson, WY, 2017, pp. 77-80.

[7] A. Muthiah, S. Ajitha, M. Thangam K.S., V. Vikram K., K. Kavitha and R. Marimuthu, "Maternal ehealth Monitoring System using LoRa Technology," 2019 IEEE 10th International Conference on Awareness Science and Technology (iCAST), Morioka, Japan,2019, pp. 1-4.

[8]S. Mukherjee, A. Ghosh and S. K. Sarkar, "Arduino based Wireless Heart-rate Monitoring system with Automatic SOS Message and/or Call facility using SIM900A GSM Module," 2019 International Conference on Vision Towards Emerging Trends in Communication and Networking (ViTECoN), Vellore, India, 2019, pp. 1-5.

.[9]A. Rahman, T. Rahman, N. H. Ghani, S. Hossain and J. Uddin, "IoT Based Patient Monitoring System Using ECG Sensor," 2019 International Conference on Robotics,Electrical and Signal Processing Techniques (ICREST), Dhaka, Bangladesh, 2019, pp. 378-382.

[10]A. Zourmand, A. L. Kun Hing, C. Wai Hung and M. AbdulRehman, "Internet of Things (IoT) using LoRatechnology," 2019 IEEE International Conference on Automatic Control and Intelligent Systems (I2CACIS), Selangor, Malaysia, 2019, p. 324-330.

[11] A. A. Galadima, "Arduino as a learning tool," $201411^{\text {th }}$ International Conference on Electronics, Computer and Computation (ICECCO), Abuja, 2014, pp. 1-4. 